\title{
Traumatic Abdominal Hernia Masquerading as Strangulated Spigelian Hernia
}

\author{
${ }^{1} \mathrm{D}$ Nagarajan, ${ }^{2}$ Malarvizhi Chandrasekhar, ${ }^{3} \mathrm{Jim}$ Jebakumar, ${ }^{4}$ Aravind Menon
}

\section{ABSTRACT}

Spigelian hernia is a rare hernia constituting 0.1 to $2 \%$ of all hernias and needs high degree of clinical suspicion to diagnose. It has high chances of strangulation and hence operative management is advised. Traumatic abdominal wall hernia (TAWH) is yet another type of rare hernia usually occurring due to blunt trauma. This patient presented with TAWH with features of strangulation, at the anatomical site of Spigelian hernia mimicking a strangulated Spigelian hernia. He underwent emergency exploratory laparotomy, resection and anastomosis of involved small bowel segment with anatomical repair of defect. Patient recovered uneventfully in postoperative period.

Keywords: Post-traumatic, Spigelian, Strangulated hernia, Trauma, Traumatic hernia.

How to cite this article: Nagarajan D, Chandrasekhar M, Jebakumar J, Menon A. Traumatic Abdominal Hernia Masquerading as Strangulated Spigelian Hernia. Panam J Trauma Crit Care Emerg Surg 2015;4(2):103-106.

Source of support: Nil

Conflict of interest: None

\section{RESUMEN}

Una hernia Spiegeliana es rara que constituye una 0,1 a $2 \%$ de todas hernias y necesita de un alto grado de sospecha clínica para el diagnóstico. Cuenta con altas posibilidades de estrangulamiento y por lo tanto se aconseja menejo quirúrgico. Hernias traumáticas de la pared abdominal (TAWH) es otro tipo de hernia rara que ocurre generalmente debido a traumatismo. Este paciente se presentó con TAWH con características de estrangulamiento, en el sitio anatómico de hernia de Spiegel imitando una hernia de Spiegel estrangulada. Se sometió a laparotomía exploratoria de emergencia, resección y anastomosis de segmento del intestino delgado involucrado con la reparación anatómica del defectos. El paciente se recuperó sin problemas en el postoperatorio. Palabras clave: postraumático, Spiegel, hernia estrangulada, Trauma, hernia traumática.

Palabras claves: Hernia estrangulada, Hernia traumática, Postraumático, Spiegel, Trauma.

\footnotetext{
${ }^{1}$ Professor, ${ }^{2,3}$ Assistant Professor, ${ }^{4}$ Postgraduate

${ }^{1-4}$ Department of General Surgery, Stanley Medical College Chennai, Tamil Nadu, India
}

Corresponding Author: Aravind Menon, Postgraduate Department of General Surgery, Stanley Medical College Chennai, Tamil Nadu, India, Phone: 04425281351, e-mail: aravindmenonk@gmail.com

\section{INTRODUCTION}

Abdominal wall hernia caused by blunt trauma are a rare group of hernias encountered in clinical practice. Traumatic abdominal wall hernia (TAWH) is one among the rarer hernias with around 50 cases reported worldwide. ${ }^{2,3}$ The etiology in most of the cases is due to blunt trauma to abdomen causing shear force to separate or tear the supporting muscle layers of the abdomen resulting in a hernia. Three types of such hernias have been described by Wood et al: (i) high energy trauma causing large defect, (ii) low energy trauma causing small defect, (iii) deceleration injuries ${ }^{1}$ causing bowel loop herniation. Spigelian hernia is yet another rare hernia constituting 0.1 to $2 \%$ of all hernias and needs high degree of clinical suspicion to diagnose. ${ }^{1}$ This patient presented with a strangulated TAWH at the anatomical site of Spigelian hernia. Preoperative imaging studies were reported as strangulated Spigelian hernia. Intraoperatively, the abdominal wall defect with a peritoneal rent was identified, anatomical repair was done with resection and anastomosis of involved bowel segment. This case is reported for its rarity of presentation and to emphasize the importance of history and physical examination in preoperative planning even in the setting of an emergency surgery.

\section{CASE REPORT}

A 29-year-old male presented to the emergency ward with complaints of abdominal pain, constipation and vomiting for 10 days. On eliciting history, he gave history of a road traffic accident 15 days back and sustaining blunt injury to anterior abdominal wall with handle bar of autorickshaw along with multiple lacerations to anterior abdominal wall which was sutured in a private clinic on the day of injury. Post-trauma, he was asymptomatic for 5 days. On examination, he had tenderness in the region of left iliac fossa. A mass of size $3 \mathrm{~cm}$ diameter with ill defined borders was palpable in the left iliac fossa in the subcutaneous plane and was irreducible. In addition, he had tachycardia and gross dehydration and was febrile. A probable diagnosis of strangulated Spigelian hernia was made keeping in mind the anatomical site as well as the history of trauma. He was resuscitated with intravenous fluids. Blood investigations revealed raised total count with leukocytosis. 

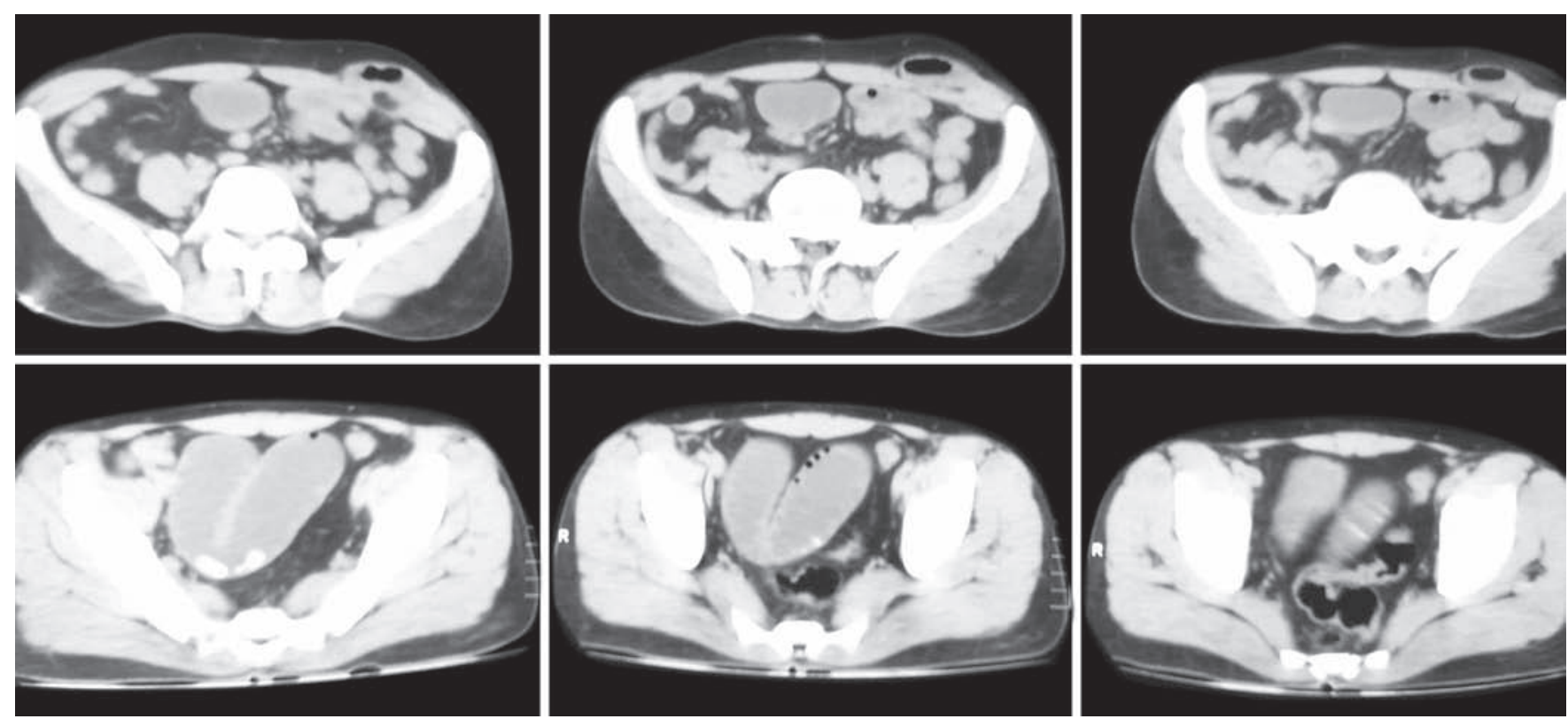

Fig. 1: Preoperative computerized tomograph mimicking a strangulated Spigelian hernia

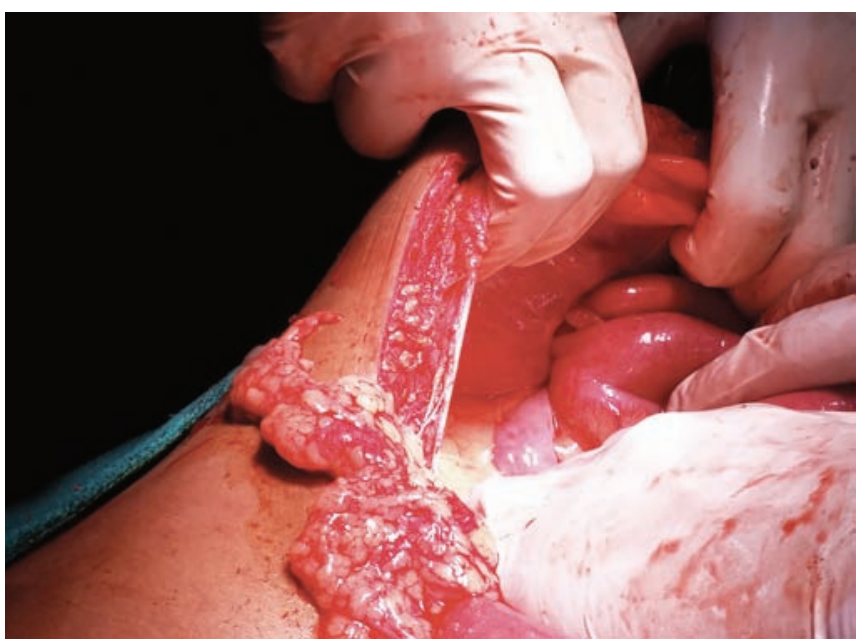

Fig. 2: Bowel loops herniating through the peritoneal rent

Computerized tomograph of the abdomen was reported as strangulated Spigelian hernia with dilated bowel loops (Fig. 1). We planned for an exploratory laparotomy. The abdomen was opened through a midline incision and the following findings were noted on exploration:

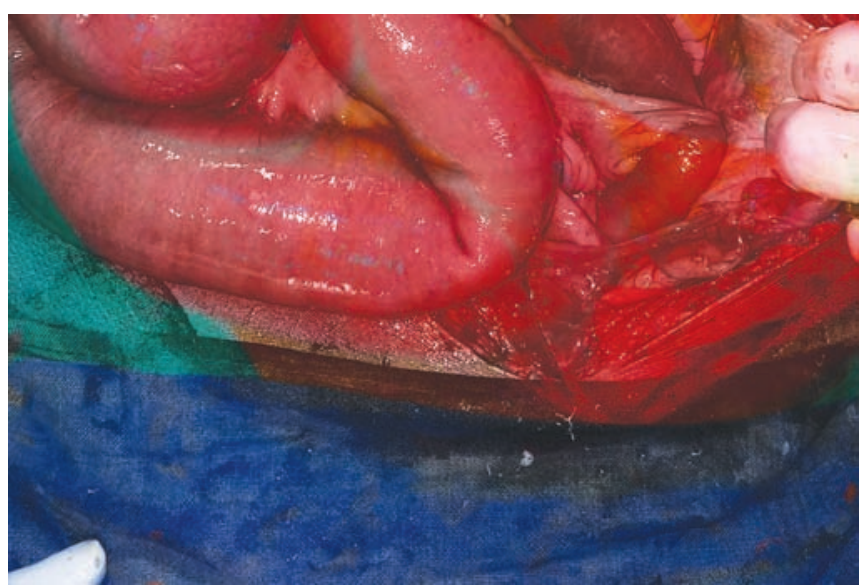

Fig. 3: Traumatic hernia with bowel loops as content
1. Rent in the peritoneum with disruption of muscle layers causing interparietal herniation and obstruction of bowel loops (proximal ileum) and dilatation of proximal bowel (Fig. 2 to 4).

2. Absence of any hernial sac containing the bowel loops ruling out a Spigelian hernia (Fig. 3).

3. Other solid organs and hollow viscera were normal. The muscle tear was enlarged with cautery and obstructed bowel loops were taken out through the rent in the peritoneum. Though the loops were healthy, a constricting ring was found to obstruct normal peristalsis (Fig. 4).

Keeping in mind the young age of the patient, the involved $20 \mathrm{~cm}$ of bowel including the constriction ring was resected and primary ileoileal anastomosis was done. The tear in the peritoneum and muscle layers which caused the hernia was repaired by layered suturing (Fig. 5).

Patient developed wound infection in the 4 th postoperative day which was managed conservatively with antibiotics. Patient recovered well and was discharged on 14 th postoperative day.

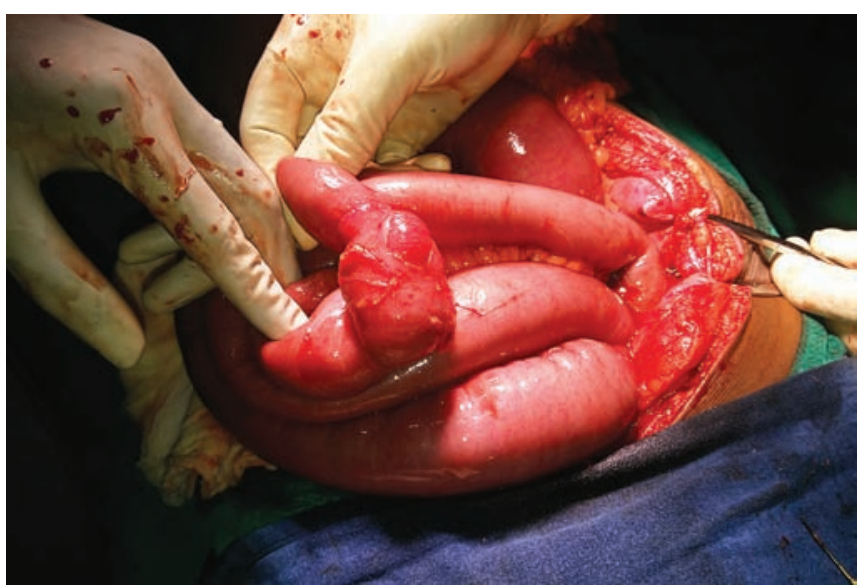

Fig. 4: Obstructed bowel loops with constriction ring 


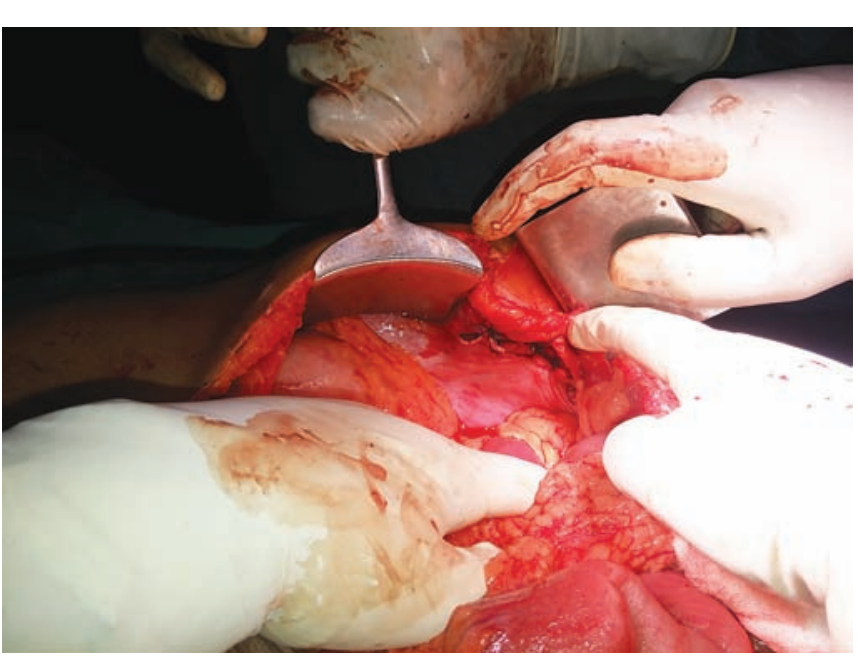

Fig. 5: After primary tension-free layered repair of the defect

\section{DISCUSSION}

Traumatic abdominal wall hernia was first described by Selby ${ }^{3}$ in 1906. It was defined as immediate appearance of hernia through the disrupted muscle and fascia after blunt abdominal trauma, and failure of the injury to penetrate the skin by Damschen et al. ${ }^{6}$ The only available classification for these hernia is by Wood et al who classified it into three types:

1. Large defect usually caused from high velocity, high energy blunt force; commonly associated with visceral injury, e.g. fall from height.

2. Small defect associated with low velocity, low energy impact; visceral injuries less common, e.g. two wheeler handle bar injury.

3. Bowel loop herniation due to decelaration injuries. These are extremely rare.

The clinician must examine the patient with a high index of suspicion as most cases of TAWH are associated with visceral injuries. History is very contributory and a proper history can clinch the diagnosis. Computerized tomograph preferably contrast enhanced, is the investigation of choice. ${ }^{4,5}$

Management is invariably surgical as chances for obstruction or strangulation is relatively high. High velocity injuries usually demand a thorough exploratory laparotomy as these are associated with visceral injuries. Many surgeons debate the necessity of this. ${ }^{7}$

Small hernias may be operated by local incisions. ${ }^{8}$

In the event of suspected visceral injury, diagnostic laparoscopy and proceed is a reliable option. ${ }^{5}$

We follow early exploration and repair for cases of traumatic hernia in our center. Some surgeons prefer delayed reconstruction of the abdominal wall ${ }^{9}$ defect though we do not recommend this. This is due to the probability that the trauma sustained to the muscles and fascia may go for secondary contracture causing a difficulty in approximation of the defect and undue tension in delayed repair.

We did an anatomical repair of the defect safely with absorbable sutures as we could achieve tension free approximation. Nonabsorbable sutures may have an advantage though previous reports show no disadvantages in using absorbable sutures..$^{10-12}$

The option of prosthetic mesh repair has been highlighted by many authors. ${ }^{13,14}$ We agree that mesh repair has its own advantages in preventing long-term recurrence after traumatic hernia repair. ${ }^{4}$ But in cases of emergency surgery if tension free layer by layer repair is achievable, it is to be preferred as it saves much of the operating time in an emergency setting required for a mesh repair. However, repair of large defects may be reinforced with a prosthetic mesh to avoid long-term complication of recurrence in the absence of intra-abdominal sepsis..$^{15}$ We leave the choice of primary repair or prosthetic mesh repair to the specificity of the case and surgeon's preference.

Overall, the trauma surgeons must have a good knowledge of the entity of TAWH for timely diagnosis and to choose the correct management for the benefit of the patient. We recommend early timely surgical exploration with layered anatomical tension-free repair of the defect as a safe management option in such patients.

\section{REFERENCES}

1. Montes IS, Deysine M. Spigelian and other common hernia repairs. Surg Clin North Am 2003;83(5):1235.

2. Lane $\mathrm{CT}$, Cohen AJ, Cinat ME. Management of traumatic abdominal wall hernia. Am Surg 2003;69(1):73-76.

3. Selby CD. Direct abdominal hernia of traumatic origin. JAMA 1906;47(18):1485-1486.

4. Choi HJ, et al. Traumatic abdominal wall hernia: a case study highlighting surgical management. Yonsei Med J 2007; 48(3):549-553.

5. Aravinda PS, et al. Traumatic Spigelian hernia: a rare clinical scenario. J Clin Diag Res 2014 May;8(5):D01-ND02.

6. Damschen DD, Landercasper J, Cogbill TH, Stolee RT. Acute traumatic abdominal hernia: case reports. J Trauma 1994; 36(2):273-276.

7. Perez VM, Mc Donald AD, Ghani A, Bleacher JH. Handlebar hernia: a rare traumatic abdominal wall hernia. J Trauma 1998;44(3):568.

8. Goliath J, Mittal V, McDonough J. Traumatic handlebar hernia: a rare abdominal wall hernia. J Pediatr Surg 2004; 39(10):e20-e22.

9. Kubalak G. Handlebar hernia: case report and review of literature. J Trauma 1994;36(3):438-439.

10. Shiomi H, Hase T, Matsuno S, Izumi M, Tatsuto T, Ito F, et al. Handlebar hernia with intra-abdominal extraluminal air presenting as novel form of traumatic abdominal wall hernia: report of a case. Surg Today 1999;29(12):1280-1284. 
11. Fraser N, Milligan S, Arthur RJ, Crabbe DC. Handlebar hernia masquerading as an inguinal hematoma. Hernia 2002;6(1): 39-41.

12. Iunuma $Y$, Yamazaki $Y$, Hirose $Y$, Kinoshita H, Kumagai $K$, Tanaka $\mathrm{T}$, et al. A case of a traumatic abdominal wall hernia that could not be identified until exploratory laparoscopy was performed. Pediatr Surg Int 2005;21(1):54-57.
13. Vargo D, Schurr M, Harms B. Laparoscopic repair of a traumatic ventral hernia. J Trauma 1996;41(2):353-355.

14. Mancel B, Aslam A. Traumatic abdominal wall hernia: an unusual bicycle handlebar injury. Pediatr Surg Int 2003;19(11):746-747.

15. Santora TA, Roslyn JJ. Incisonal hernia. Surg Clin North Am 1993;73(3):557-570. 